\title{
Glucose Transport in Brain and Retina: Implications in the Management and Complications of Diabetes
}

\author{
Arno K. Kumagai* \\ Department of Internal Medicine, \\ Michigan Diabetes Research and \\ Training Center, University of \\ Michigan Medical School, Ann Arbor, \\ MI, USA \\ *Correspondence to: Department of \\ Internal Medicine, 5570 MSRB-2, \\ University of Michigan Medical \\ School, Ann Arbor, MI 48109-0678, \\ USA \\ E-mail: akumagai@umich.edu
}

\begin{abstract}
Summary
Neural tissue is entirely dependent on glucose for normal metabolic activity. Since glucose stores in the brain and retina are negligible compared to glucose demand, metabolism in these tissues is dependent upon adequate glucose delivery from the systemic circulation. In the brain, the critical interface for glucose transport is at the brain capillary endothelial cells which comprise the blood-brain barrier (BBB). In the retina, transport occurs across the retinal capillary endothelial cells of the inner blood-retinal barrier (BRB) and the retinal pigment epithelium of the outer BRB. Because glucose transport across these barriers is mediated exclusively by the sodiumindependent glucose transporter GLUT1, changes in endothelial glucose transport and GLUT1 abundance in the barriers of the brain and retina may have profound consequences on glucose delivery to these tissues and major implications in the development of two major diabetic complications, namely insulin-induced hypoglycemia and diabetic retinopathy. This review discusses the regulation of brain and retinal glucose transport and glucose transporter expression and considers the role of changes in glucose transporter expression in the development of two of the most devastating complications of longstanding diabetes mellitus and its management. Copyright (C) 1999 John Wiley \& Sons, Ltd.
\end{abstract}

Keywords blood-brain barrier; blood-retinal barrier; glucose transport; hypoglycemia; diabetic retinopathy; diabetes

\section{Introduction}

Glucose is an essential metabolic substrate of all mammalian cells. Neural tissue in particular, i.e. the brain and retina, is entirely dependent on glucose under normal physiological conditions; however, access of neural tissues to a steady supply of this nutrient is limited by two factors. First, glycogen stores within neural tissue are either non-existent (e.g. brain) or inadequate to meet basal metabolic demands (e.g. retina). This relative lack of local carbohydrate stores results in a total dependence of neural tissue on delivery of glucose from the circulation [1,2]. Second, each of these tissues possesses a barrier between itself and its blood supply. In the brain, the presence of tight junctions and a lack of fenestrations and pinocytotic activity characterize the microvascular endothelial cells that comprise the BBB [3]. In the retina, two barriers exist: the retinal capillary endothelial cells of the inner BRB, a microvascular bed which is highly similar to that in the brain, and the retinal pigment epithelium, a single layer of epithelial cells connected by tight junctions which is located between the photoreceptor elements and the choroid and is known as the outer BRB [4]. The presence of these barriers in 
neural tissue prevents the passive diffusion of glucose and other blood-borne nutrients into the interstitial space surrounding neural cells. Instead, glucose entry is mediated by a specific, saturable, facilitated transport process involving members of the sodium-independent glucose transporter family (Table 1 ) $[5,6]$. The purpose of the present review is to discuss glucose transport and glucose transporter expression in the brain and retina and their respective barriers. The review also discusses the possible implications that changes in brain and retinal glucose transport may have in the pathogenesis of a complication associated with the treatment of diabetes (iatrogenic hypoglycemia) and of one of the sequelae of long-term hyperglycemia (diabetic retinopathy).

Five functional isoforms of the GLUT family have been identified and are numbered in the order of their characterization. The various glucose transporter isoforms demonstrate, at least to a certain degree, tissuespecific localization $[5,6]$. GLUT1, the first isoform cloned [7], is expressed in high density in the membranes of human erythrocytes and is characteristically expressed in blood-tissue barriers, such as the BBB, the blood-ocular barriers and the blood-placental and blood-testis barriers $[2,8,9]$. GLUT2 is expressed predominantly in the liver and in pancreatic $\beta$-cells [10], where, functionally coupled to hexokinase, it plays a role in sensing blood glucose levels. GLUT3, originally isolated from a fetal muscle cell line [11], has been identified as the primary glucose transporter in neural elements of the brain [12]. GLUT4 is expressed in high abundance in skeletal muscle and fat [13,14], where it mediates insulin-sensitive glucose transport, and GLUT5 is a fructose transporter that is expressed predominantly in intestinal epithelium [15]. The glucose transporter isoforms share 39-65\% amino acid sequence identity [5], and sequence comparisons between GLUT1 of various species reveal an extremely high degree of conservation (>95\%) [16], thus emphasizing the critical and universal importance of this transporter in cellular metabolism. Hydrophobicity sequence analysis suggests that the GLUTs are arranged in 12 membrane-spanning regions [7]. In the case of GLUT1, there is a single N-linked glycosylation site at $\mathrm{Asp}_{45}$ in the first extracellular loop [7]. Differential glycosylation of this residue accounts for the different molecular weights of GLUT1 in different cell types [17] and may play a role in the subcellular localization of GLUT1 [18,19]. The sodium-independent glucose transporters mediate transport of glucose, glucose analogs and other hexoses, with conformational specificity (i.e. transporting D- but not L-isomers) and different affinities for hexoses and glucose analogs. In addition, GLUT1 and GLUT3 have been demonstrated to be responsible for the transport of ascorbic acid [20], which, in brain capillary endothelia, is transported in its oxidized form [21].

\section{Glucose transport and glucose transporters in brain}

Glucose transport from the blood into the cytosol of the neuronal elements of the brain occurs across several membranes in series. Glucose first enters the cytoplasm of the endothelial cells of the BBB by transport across the endothelial lumenal membrane via GLUT1. Subsequent transport across the ablumenal membrane and into the interstitial space is also mediated by the GLUT1 isoform. Finally, glucose uptake into the cytosol of the neuronal cells occurs via the neuronal GLUT3 glucose transporter $[22,23]$. Cytochalasin-B binding studies suggest that the density of glucose transporters on the BBB is $2-3$ times that on the neuronal cells [24]; however, because the surface area of the BBB is less than $0.1 \%$ of that of the neuronal elements of the brain, transport of glucose from blood into brain is limited by its transport across the BBB [1].

In studies using light microscopic immunohistochemistry and in situ hybridization of rat brain sections, GLUT1 is localized to the endothelia of the BBB [24]. Northern blotting analysis of bovine brain capillary total RNA [25] and rat brain poly(A+) mRNA [26] demonstrates a characteristic 2.8-kb band corresponding to the GLUT1 transcript, and GLUT1 mRNA is not detected in bovine and rat brain which has been depleted of vascular elements $[25,26]$. These observations have lent support to the hypothesis that GLUT1 is exclusively expressed in the endothelial cells of the $\mathrm{BBB}[24,25]$. In contrast, GLUT1 is clearly detectable as a band of $45 \mathrm{kDa}$ on Western blots of vascular-depleted brain protein, compared to the broad 54-kDa band seen in preparations of isolated brain capillaries [19,24,27]. The difference in molecular weight between 'vascular' and 'non-vascular' GLUT1 is due to differential glycosylation of the aspargine residue in the first extracellular loop of the transporter, with a larger carbohydrate side chain on the vascular form of GLUT1 [19,24]. Localization of 'nonvascular' GLUT1 has been attributed to glial cells: using in situ hybridization, Bondy and colleagues have reported in rat brain sections scattered signals for GLUT1 transcript which

Table 1. Isoforms of the sodium-independent facilitative glucose transporter family and their characteristic tissue localization

\begin{tabular}{lll}
\hline GLUT isoform & Tissue localization & Comments \\
\hline GLUT1 & $\begin{array}{l}\text { Human erythrocyte, blood-brain barrier, blood-retinal barriers, } \\
\text { blood-placental barrier, blood-testis barrier }\end{array}$ & Characteristically expressed in cell types with barrier functions \\
GLUT2 & Liver, pancreatic $\beta$-cell & Participates in pancreatic glucose sensing \\
GLUT2 & Brain & Major transporter in CNS neural tissue \\
GLUT4 & Fat, skeletal muscle, myocardial tissue & Insulin-sensitive \\
GLUT5 & Intestinal epithelium & Fructose transporter \\
\hline
\end{tabular}


appear to localize to astrocytes [28], and in recent studies, McCall and co-workers have reported specific staining for GLUT1 in the parenchyma of normal rat brains which colocalizes with glial fibillary acidic protein (GFAP), a specific marker of cells of glial origin [29]. Furthermore, $\mathrm{Yu}$ and co-workers have demonstrated GLUT1 immunoreactivity in rat brain glia and oligodendrocytes by electron microscopic immunohistochemistry [30]. Additional, indirect evidence of GLUT1 in brain glial cells is the abundant expression of GLUT1 protein and transcript in primary cultures of rat brain glial cells [31]. These latter data, however, must be interpreted with caution, since GLUT1 may be expressed in most cells in culture, even in cell types which do not express the protein in vivo [6]. Nonetheless, evidence from cytochalasin-B binding assays [32] and immunohistochemical $[24,29]$ and in situ hybridization studies $[24,28]$ suggest that GLUT1 is predominantly expressed on the BBB.

At a subcellular level, GLUT1 is localized to both the luminal and abluminal membranes of the endothelial cells of the rat BBB, and approximately $40 \%$ of total cellular GLUT1 in the rat BBB resides in the cytosol [33]. An asymmetrical distribution of GLUT1 between the luminal and abluminal membranes of the rat BBB has been documented, in which the ratio of luminal to abluminal transporters is approximately $1: 4$ [33], an observation which suggests that glucose transport at the BBB is limited at the lumenal membrane. This pattern of asymmetrical distribution has been reported in the BBB of the developing rabbit as well [34]. Taken together, these data suggest that the lumenal membrane of the endothelial cells represents a critical interface for glucose entry into brain: BBB glucose transport may be upregulated by either increased expression of GLUT1 or, in a more acute setting, by translocation of pre-existing cytosolic transporters to the lumenal membrane [34].

As mentioned above, GLUT3 has been identified as the principal glucose transporter isoform in neural cells in brain. Gerhart and co-workers have used an antiserum directed against the carboxyl terminus of human GLUT3 to report the presence of GLUT3 in the canine BBB as well [35]; however, this observation has been challenged by others [27], who cite a lack of specificity between human and canine carboxyl terminus amino acid sequences of this transporter isoform. Based on numerous studies, a consensus has emerged that in the brain, GLUT3 is localized to the neuropil [27,36,37]. With regard to expression of other glucose transporter isoforms on the microvasculature of the brain, studies from other laboratories have reported the apparent localization of GLUT2 in the hypothalamus [38], and the insulinsensitive transporter, GLUT4, in the BBB of the frontal cortex [39]. The presence of the latter isoform - albeit, at very low abundance - on the BBB is intriguing, since glucose uptake by the brain is thought to be insulininsensitive [1]. BBB expression of GLUT5, the fructose transporter [40], and of a sodium-dependent glucose cotransporter similar to SGLT2 [41] have also been reported. Nonetheless, the extremely close agreement between the density of D-glucose-displaceable cytochalasin-B binding sites and immunoreactive GLUT1 abundance on isolated brain capillary preparations [42] provides evidence that glucose transport across the $\mathrm{BBB}$ is predominantly mediated by GLUT1.

Although glucose transport into whole brain has been extensively studied in both animal models [26,43-45] and human subjects [46], it is clear that there is a great deal of heterogeneity in brain glucose uptake and utilization in different brain regions [47-50]. Glucose transporter gene expression in the brain also demonstrates regional variation [51,52]. For example, GLUT1 is expressed in higher density in gray matter than white matter, and its expression is positively correlated with regional glucose utilization [52]. GLUT3 expression shows regional heterogeneity; however, unlike GLUT1, there is no correlation with regional glucose consumption [53]. Western blotting studies by Brant and co-workers using isoform-specific antisera demonstrate that GLUT2 is expressed at low levels throughout the rat brain, with the highest levels in the optic chiasm and pituitary. In contrast, GLUT4 expression is predominantly limited to the pituitary, hypothalamus and cerebellum [51]. (The apparent contradiction between an inability to detect GLUT4 in frontal cortex by Western blotting by Brant et al. [51] and the presence of GLUT4 in microvessel preparations reported by McCall et al. [39] may be explained by the extremely low abundance of GLUT4, in comparison to that of GLUT1, in the frontal cortex [39].)

\section{Regulation of glucose transporter expression in brain}

In the brain, GLUT1 expression is subject to developmental regulation with a decrease in immunoreactive GLUT1 in the immediate postnatal period, followed by a gradual increase in localization of GLUT1 to the BBB and an increase in its abundance to levels comparable to those in adults by $30-60$ days after birth $[42,54,55]$. The gradual increase in BBB GLUT1 expression and decrease in parenchymal (i.e. nonvascular) GLUT1 correlate with the maturation of the BBB in the rat brain [56]. The neuronal glucose transporter GLUT3 also undergoes developmental regulation, which coincides with neuronal maturation [57].

In studies using bovine brain endothelial cell cultures, an in vitro model of the BBB, GLUT1 mRNA expression has been shown to be upregulated in response to glucose deprivation [58,59], phorbol esters and serum [60] and growth factors, including tumor necrosis factor- $\alpha$ (TNF- $\alpha$ ) [61], brain-derived peptides [62] and glial-derived factors $[63,64]$. Of note, GLUT1-mediated glucose transport in brain capillary endothelial cells is not affected by insulin [65], an observation which supports the concept that BBB glucose transport is insulin-insensitive [1]. Upregulation of brain microvascular endothelial GLUT1 abundance in response to glucose deprivation appears to be regulated at a post-transcriptional level, since nuclear 
run-on assays of bovine brain endothelial cells grown in media at low glucose concentrations demonstrate transcription rates which are similar to that of controls [59]. Actinomycin D studies of these cell cultures reveal a prolongation of the half-life of the GLUT1 transcript in glucose-deprived cell cultures, suggesting that the increase in GLUT1 mRNA (and by inference, in immunoreactive GLUT1 protein) during glucose deprivation occurs via stabilization of the GLUT1 transcript [59].

In animal models, BBB glucose transport and/or GLUT1 abundance has been shown to be modulated by streptozotocin-induced diabetes $[44,45,66]$, chronic hypoglycemia [26,67-69], localized cerebral ischemia [29,70-72] and seizures [73,74]. In human brain samples, GLUT1 abundance has been reported to be decreased in the neocortex and hippocampus in Alzheimer's disease [75], and GLUT1 and GLUT3 have been reported to be decreased in the caudate and putamen in Huntington's disease [76]. Astrocytoma, a central nervous system tumor of glial cell origin, demonstrates an increase in GLUT1 and GLUT3 mRNA with increasing grade of malignancy; however, only immunoreactive GLUT3 protein is detected in the highest grade gliomas $[77,78]$. An absence of GLUT1 protein despite a relative high abundance of GLUT1 mRNA in high-grade gliomas has been explained by post-transcriptional modification of the GLUT1 mRNA: a 48-kDa cytosolic protein which is overexpressed in high-grade gliomas acts in trans to bind to specific sequences within the $3^{\prime}$ untranslated region (3' UTR) of the GLUT1 mRNA. This interaction apparently results in destabilization of the GLUT1 transcript and gives rise to a discordance between the abundance of GLUT1 mRNA and immunoreactive protein [79].

Glucose transport and glucose transporter gene expression may be upregulated in situations of physiological stress to compensate for increased metabolic demand. Experimental brain ischemia produced by middle carotid artery occlusion results in upregulation of GLUT1 transcript both at the $\mathrm{BBB}$ and in brain parenchyma [70,71], a change which apparently is associated with a similar upregulation in GLUT1 protein [29]. The protective role of GLUT1 upregulation in brain has been observed in studies using replication-defective herpes simplex viral vectors to induce GLUT1 overexpression in neurons in vitro and in vivo: GLUT1 overexpression protects cultured neuronal cells against hypoxia-induced necrosis [80] and protects hippocampal neurons against ischemic injury and death in a rat model of stroke [81]. Compensatory increase of GLUT1 abundance on the BBB has been reported in a resected seizure focus of human brain [73], and upregulation of brain GLUT1 and GLUT3 have been reported in an animal model of chronic seizures [74]. The critical role of GLUT1-mediated BBB glucose transport in the provision of substrate to the brain is also evidenced by the report of seizures, developmental delay and hypoglycorrachia (low cerebrospinal fluid glucose concentrations) in two infants with a haploinsufficiency of GLUT1 [82].

Downregulation of glucose transport into brain has been reported in streptozotocin- and alloxan-induced as well as spontaneous diabetes in rats [44,45,66,83], a change that is secondary to a decrease in glucose transporter density at the BBB $[45,84]$. This decrease in $\mathrm{BBB}$ glucose transport and the consequent relative neuroglycopenia have been proposed as the basis for the neuroglycopenic symptoms experienced at normoglycemic levels in some individuals with poorly controlled diabetes when hyperglycemia is rapidly corrected [85-87]. The observation of decreased BBB glucose transport and/or GLUT1 expression in experimental diabetes, however, has not been universally accepted: studies from other laboratories have reported either unchanged or increased BBB glucose transport or GLUT1 density in this setting [69,88-90]. Furthermore, the concept of decreased cerebral metabolic rates due to a relative neuroglycopenia in individuals with poorly controlled diabetes has been called into question. Increased regional cerebral metabolic rates have been observed in streptozotocin diabetic rats following acute normalization of blood glucose levels [91], and more recently, positron emission tomography has failed to demonstrate a significant change in brain glucose metabolism or BBB glucose transport in individuals with poorly controlled diabetes, compared to nondiabetic controls [92]. Changes in BBB glucose transport and GLUT1 expression in the setting of suboptimally controlled diabetes is the subject of ongoing controversy $[45,69,93]$.

With regard to changes in BBB GLUT1 in diabetes, an apparent discordance has been observed between the abundance of GLUT1 mRNA and protein in the BBB, similar to that seen in high-grade gliomas: in streptozotocin diabetic rats, BBB glucose transport and GLUT1 protein are downregulated [45], whereas the abundance of GLUT1 transcript is actually increased [94]. It is currently not known whether this apparent post-transcriptional modulation of BBB GLUT1 expression is also due to specific RNA-protein interactions such as those reported in high-grade gliomas [79].

\section{Brain glucose transport in iatrogenic hypoglycemia}

The hope inspired by the results of the Diabetes Control and Complications Trial (DCCT) [95] - that intensive insulin therapy with near-normalization of blood glucose levels leads to dramatic reductions in the risk of development and progression of microvascular complications - is tempered by the sobering realization that intensive insulin therapy is associated with a significant increase in risk for severe hypoglycemia [96]. Indeed, iatrogenic hypoglycemia has been referred to as the 'principal obstacle in the treatment of insulin-dependent diabetes' [97].

Accumulating clinical evidence has suggested that the increased risk of severe hypoglycemia experienced by individuals who undergo intensive insulin therapy is due 
to changes in the intricate feedback system which defends against declining blood glucose levels known as the counterregulatory response [97-102]. In a non-diabetic individual, falling blood glucose levels trigger a hierarchy of hormonal responses, which includes inhibition of insulin secretion, followed by the sequential release of glucagon, epinephrine and norepinephrine, cortisol, and growth hormone [103]. The net result of this crescendo of hormonal responses is to raise the blood glucose level. In non-diabetic individuals, the principal defense against hypoglycemia is production of glucagon from the $\alpha$-cells of the pancreas and the resultant stimulation of hepatic gluconeogenesis [104]. In the setting of insulin-dependent diabetes, however, several defects exist in the counterregulatory response, including a loss of hypoglycemia-stimulated glucagon secretion relatively early in the course of the disease $[105,106]$. Consequently, individuals with Type 1 diabetes mellitus (DM) learn to depend on autonomic (predominantly adrenergic) 'warning symptoms', including palpitations, tremulousness, sweating, anxiety and warmth, to know when to seek carbohydrate replacement [104]. Normally, the counterregulatory response - and its associated autonomic warning symptoms - is triggered at a blood glucose concentration higher than that eliciting neuroglycopenic symptoms such as confusion, disorientation, stupor, coma and seizures [103]. The autonomic symptoms thus allow the individual with Type 1 DM to recognize the development of hypoglycemia and to seek corrective measures. Conversely, the loss of autonomic warning symptoms in the face of declining blood glucose levels that is associated with an absence or significant impairment of the counterregulatory response is responsible for the phenomenon of 'hypoglycemic unawareness' in which an individual with Type 1 DM develops cognitive dysfunction without prior warning symptoms. The practical consequence of this condition is the inability of an individual with diabetes to perceive and treat episodes of hypoglycemia before cognitive impairment and more severe hypoglycemia occur [107].

An accumulating body of evidence suggests that with the institution of intensive insulin therapy, the glycemic threshold for the counterregulatory response shifts to a lower blood glucose concentration $[99,100,108]$. Amiel and co-workers have used insulin clamp studies to demonstrate that the counterregulatory response in individuals with well-controlled diabetes, i.e. with $\mathrm{HbA}_{1 \mathrm{c}}$ values of $7.6 \pm 0.7 \%$, is elicited at a lower blood glucose level than that seen in individuals with poorly controlled diabetes $\left(\mathrm{HbA}_{1 \mathrm{c}}\right.$ of $\left.11.5 \pm 1.7 \%\right)$ and in nondiabetic control subjects [99]. Furthermore, institution of intensive insulin therapy in a subset of the subjects with poor control is associated with the development of an identical impairment of counterregulation, like that seen in the well-controlled group [99]. The stimulus for the change in the counterregulatory threshold appears to be the often-unrecognized episodes of intermittent hypoglycemia which individuals with Type 1 DM under intensive insulin therapy experience on a daily basis $[109,110]$.
Impairment of the counterregulatory response due to intermittent episodes of mild to moderate hypoglycemia may result in impaired perception of hypoglycemia, which in turn may act in a vicious cycle in predisposing an individual with Type $1 \mathrm{DM}$ to further, more severe hypoglycemia [111]. Individuals in whom warning symptoms are lost, i.e. those with hypoglycemia unawareness, have an approximately 6-fold increased risk of severe hypoglycemia compared to individuals with Type 1 DM and an intact warning system [112], and although the cumulative effects of mild or moderate hypoglycemia on cognitive function are not certain, recurrent episodes of severe hypoglycemia are well known to result in permanent memory loss and cognitive problems [113].

As alluded to in the remarks above, the most vulnerable organ to the acute and chronic effects of hypoglycemia is the brain. The absolute reliance of the brain on glucose as its principal metabolic substrate and the relative lack of local stores of glycogen underlie the brain's selective vulnerability to hypoglycemia-mediated injury and its dependence on glucose transport across the BBB. Furthermore, under normal physiological conditions, phosphorylation of glucose within the neuronal cytosol by hexokinase occurs at a rate approximately half that of glucose transport and is normally the limiting step in brain glucose metabolism [1]. In hypoglycemia, however, brain hexokinase activity decreases out of proportion to glucose transport, and brain metabolism is limited by BBB glucose transport. Therefore, in hypoglycemia, GLUT1mediated glucose transport at the BBB becomes the critical component in determining brain metabolism [22,114].

Experimental evidence has suggested a compensatory mechanism at the level of the BBB by which the brain protects itself against hypoglycemic injury. Using three different means of inducing sustained hypoglycemia in animals - repeated injections of long-acting insulin, and insulin infusion via subcutaneous osmotic pumps and via implanted insulinomas - McCall and colleagues demonstrated an upregulation of brain glucose extraction in comparison to normoglycemic control animals [67]. Koranyi and co-workers demonstrated an approximate $40 \%$ increase in total brain GLUT1 mRNA and protein in a rat model of sustained hypoglycemia [68]. Subsequent studies by Kumagai et al. of chronic hypoglycemia in rats confirmed McCall's results of increased BBB glucose transport and demonstrated that this increase was due to increased abundance of GLUT1 mRNA and protein specifically at the BBB [26]. The compensatory nature of hypoglycemia-induced changes in BBB glucose transport has been demonstrated in studies comparing the effects of acute versus chronic hypoglycemia on cerebral metabolic rate in rats $\left(\mathrm{rCMR}_{\text {gluc }}\right)$ [50]. In contrast to the reductions seen in glucose transport and $\mathrm{rCMR}_{\text {gluc }}$ in acute hypoglycemia, glucose transport is increased, and $\mathrm{rCMR}_{\text {gluc }}$ and cortical function (as assessed by somatosensory evoked responses) are preserved in chronically hypoglycemic rats, compared to controls [50]. Taken together, these data suggest that a compensatory 
upregulation of BBB glucose transport occurs in the setting of hypoglycemia, and that this increase preserves brain function in the face of low peripheral glucose levels.

The application of the findings described above to the understanding of the pathogenesis of the increased risk for severe hypoglycemia episodes during intensive insulin therapy must, however, take into account two considerations: the nature of the hypoglycemic stimulus, and the relationship between brain glucose transport and brain sensing of hypoglycemia. As mentioned previously, the type of hypoglycemia experienced by individuals under intensive insulin therapy is intermittent $[109,110]$ and, therefore, changes in BBB glucose transport and GLUT1 expression reported in animal models of chronic or sustained hypoglycemia might not apply in the setting of intensive insulin therapy of Type 1 DM. Furthermore, it is unclear whether the changes in counterregulatory response to hypoglycemia are due to global increases in BBB glucose transport or to changes in transport in areas of the brain responsible for detection of declining blood glucose levels.

Boyle and colleagues recently investigated the relationship between changes in the counterregulatory response to hypoglycemia, hypoglycemia sensing and BBB glucose transport in individuals with various degrees of control of Type $1 \mathrm{DM}$ and in non-diabetic subjects [46]. In a subset of individuals with the most intensively controlled diabetes (glycosylated $\mathrm{Hb}$ of $7.2 \pm 0.5 \%$ ), impairment of counterregulation and hypoglycemia warning symptoms were associated with a preservation of BBB glucose transport. In contrast, individuals with less tightly controlled Type $1 \mathrm{DM}$ and non-diabetic control subjects had a decrease in BBB glucose transport in response to the same hypoglycemic stimulus [46]. The results of this study suggest that the increased risk of severe hypoglycemia observed in intensively controlled Type $1 \mathrm{DM}$ is due to a compensatory relative increase in total BBB glucose transport that results in a decreased counterregulatory response and blunted sensing of hypoglycemia by individuals under intensive insulin therapy. It is unclear, however, whether impairment of the counterregulatory response and hypoglycemia awareness observed in individuals under intensive insulin therapy are due to changes in whole brain glucose transport per se, i.e. whether preserved whole brain BBB glucose transport is responsible for the impairment in hypoglycemia sensing in these individuals. In the setting of intermittent hypoglycemia, the exact relationships between hypoglycemia sensing and counterregulatory and cognitive responses on the one hand, and regional or global changes in BBB glucose transport on the other, remain to be elucidated.

With regard to blood glucose sensing, it has long been hypothesized that the locus of glucose sensing responsible for the counterregulatory response to hypoglycemia is in the central nervous system. As demonstrated in canine studies by Biggers and co-workers, isolated hypoglycemia of the brain in the presence of systemic euglycemia may elicit a brisk counterregulatory response; in contrast, preservation of euglycemia in brain in the presence of systemic hypoglycemia abolishes the response [115]. In a series of elegant experiments in rats, Borg and co-workers provided evidence suggesting that the sensor is situated in the ventromedial hypothalamus (VMH): induction of localized, intracellular glycopenia in the VMH of rats by bilateral perfusion of 2-deoxyglucose into the two ventromedial hypothalamic nuclei results in a brisk counterregulatory response in the absence of hypoglycemia [116]. Conversely, perfusion of the VMH with concentrated glucose solutions abrogates the counterregulatory response in the setting of systemic hypoglycemia [117]. Other anatomical sites, including the liver $[118,119]$, have been proposed as glucose sensing areas and may play a role in addition to, or in lieu of, the VMH glucose sensor; nonetheless, the studies cited above provide firm evidence that the primary sensor involved in counterregulation is localized in the hypothalamus, and in particular, the VMH $[116,117]$.

The localization of different glucose transporter isoforms in the hypothalamus and whether changes occur in glucose transport and glucose transporter expression in the setting of intermittent hypoglycemia are unknown at present. In addition to neuronal GLUT3 and BBB GLUT1, the presence of the insulin-sensitive GLUT4 has been reported in the hypothalamus [51]. In a study investigating extra-pancreatic expression of glucokinase (the hexokinase isoform involved in glucose sensing in the $\beta$-cell), Jetton and co-workers expressed human growth hormone (hGH), acting as a reporter gene, in transgenic mice under the control of a glucokinase promoter [38]. Selective expression of hGH in the ventral hypothalamus in these studies suggested the possibility of glucokinase expression in this region of the brain, a finding supported by colocalization of immunoreactive glucokinase and the GLUT2 glucose transporter in the same region in normal mice [38]. The findings of Jetton's study are intriguing, because they suggest that the molecular machinery for glucose sensing in the $\beta$-cell, i.e. GLUT2-mediated glucose transport coupled with glucokinase activity, is recapitulated in an area of the brain which is responsible for hypoglycemia sensing. Additional observations, however, make the identification of the VMH as the ' $\beta$-cell of the brain' problematic: GLUT2 expression in the hypothalamus localizes to the arcuate nuclei, an area of the hypothalamus which is adjacent to the VMH $[120,121]$. GLUT2 and hexokinase, however, have not been reported in the VMH itself. Furthermore, the presence of the insulin-sensitive GLUT4 isoform in the hypothalamus raises the question of whether glucose transport in this area of the brain is modulated by insulin in addition to, or instead of, circulating blood glucose levels, a possibility suggested by 2-deoxyglucose brain autoradiographic studies in rats [122]. Clarification of possible changes in glucose transport in this critical region in the setting of intermittent hypoglycemia and the possible role of these changes in the increased risk of severe hypoglycemia experienced by individuals during intensive insulin therapy await further investigation. 


\section{Glucose transport and glucose transporters in retina}

The neuroretina, which is among the most metabolically active tissues in the body [123], is nourished by transport of glucose across the endothelial cells of the capillaries of the inner BRB and from the choroidal vessels across the retinal pigment epithelium of the outer BRB [2]. Studies in rats have demonstrated a saturable transport process for glucose and other hexoses in the retina [124,125]; however, due to the presence of two barriers and due to uncertainties over the relative contribution of each barrier to the nourishment of the retina in man, the results of in vivo studies of glucose transport are difficult to interpret [126]. Studies in isolated bovine retinal capillaries have shown a sodium- and energy-independent, saturable transport process for hexoses, with a high affinity for the D-stereoisomer of glucose, followed by the analogs 2-deoxy-D-glucose and 3-O-methyl-D-glucose, as well as D-mannose, D-galactose and D-xylose [127]. In contrast, L-glucose, ribose and fructose are not transported to any appreciable extent in these preparations [127]. As in the endothelial cells of the brain, glucose uptake by retinal endothelia occurs in excess of metabolic rates (i.e. hexokinase activity), such that a large intracellular pool of free glucose is present within the endothelial cells [127]. In vivo measurements of retinal glucose transport and metabolism by NMR spectroscopy have recently confirmed these observations in the rabbit retina: glucose transport exceeds metabolic rates by approximately 16fold [128]. A similar transport process for glucose has been described in isolated rat and bullfrog retinal pigment epithelium as well $[129,130]$.

It is now known that the mammalian eye expresses GLUT1 in a variety of cell types $[8,9,131,132]$. In the human eye, GLUT1 is expressed in the retinal capillary endothelial cells, the retinal pigment epithelium, the nonpigmented epithelium of the ciliary body, the endothelium of the canal of Schlem, and the capillaries and posterior pigmented epithelium of the iris [8,131,133]. In the endothelial cells of the human and rat inner BRB, GLUT1 is expressed on both the luminal and abluminal membranes, a critical prerequisite for GLUT1's role in the transcellular transport of glucose to the neuroretina $[134,135]$. Furthermore, in the human inner BRB, a substantial portion (approximately 50\%) of total cellular GLUT1 resides in cytosolic stores [135]. Because these transporters are not in contact with the plasma membrane surface, they are not available for glucose transport; however, in response to external stimuli, such as growth factors, these transporters may rapidly translocate to the plasma membrane where they may participate in mediating glucose entry into the endothelial cell.

In addition to the endothelial and epithelial cells of the inner and outer BRB, respectively, GLUT1 is expressed in cell bodies of the ganglion cell layer, the cell bodies of the photoreceptor elements and the Müller cells, a specialized glial cell which is oriented radially within the retina
$[131,133]$. The finding of abundant expression of GLUT1 in Müller cells is in line with evidence of glucose transport and metabolism in isolated cell preparations [136] and supports the hypothesis that this glial cell serves as a nutrient-supporting cell of the retina $[137,138]$. In addition to GLUT1, Müller cells have been reported to express GLUT2, the liver and pancreatic $\beta$-cell glucose transporter, in their foot processes [139]. The selective function of this transporter in the Müller cells, if any, is currently not known. In the human retina, the expression of GLUT3 is restricted exclusively to the processes of neuronal cells of the inner synaptic layer [131], an observation which supports the role of GLUT3 as the major neuronal glucose transporter 12]. Immunohistochemical studies have failed to document expression of the insulin-sensitive glucose transporter, GLUT4, and the fructose transporter, GLUT5, in the retina of the human eye [131].

\section{Regulation of glucose transporter expression in retina}

The factors mediating glucose transport and glucose transporter expression are not as well defined in the retina as they are in the brain. Expression of GLUT1 in the various cell types within the retina is preserved during development and is evident as early as 8 weeks of gestation [131]. In contrast, GLUT3 is not detected in the neuroretina in the fetus and localizes to the inner synaptic layer only in the adult retina [131]. As in other tissues, glucose transport and/or GLUT1 expression is modulated by hypoxia, growth factors and glucose in primary cultures of retinal endothelial cells, a cell culture model of the inner BRB [140,141] (A.K.K., in preparation). In cultured human retinal pigment epithelial cells, 2-deoxyglucose uptake and GLUT1 transcript have been shown to be upregulated in response to serum, insulinlike growth factor-1 (IGF-1), basic fibroblast growth factor (bFGF), platelet-derived growth factor (PDGF), and epidermal growth factor (EGF) [142].

\section{Inner blood retinal barrier glucose transport in retinopathy}

Diabetic retinopathy is one of the principal microvascular complications of long-standing diabetes mellitus and represents the leading cause of blindness in working age adults in the USA [143,144]. Pathologically, the characteristic lesions and changes associated with diabetic retinopathy are localized to the retinal microvasculature of the inner BRB. These changes include loss of pericytes, increased tortuosity of retinal capillaries, formation of microaneuryms, leakage of plasma proteins, capillary obliteration, and, in the most severe stages of diabetic retinopathy, neovascularization [143]. The metabolic 'culprit' behind these changes appears to be chronic exposure of the retina to the hyperglycemia 
associated with long-standing diabetes, a proposition which rests on two major lines of clinical evidence: first, the severity of retinopathy is correlated with poor glycemic control [145], and conversely, as demonstrated by the landmark DCCT, near-normalization of blood glucose levels prevents or delays the progression of diabetic retinopathy in individuals with Type 1 DM [95]. The exact biochemical and molecular mechanisms that transduce the chronic hyperglycemia of diabetes into pathological changes in the retina have yet to be fully clarified. Attention has focused on the role of several pathways in this process, including oxidative stress, activation of protein kinase C (PKC), non-enzymatic glycation and direct toxic effects of glucose on endothelial function, replication and survival [146,147]. A common denominator, however, which connects hyperglycemia with these pathways is the exposure of the intracellular milieu of the retinal capillary endothelial cell to elevated blood glucose concentrations. Indeed, increased retinal endothelial cell glucose flux is assumed in the conceptualization of several of these pathways (Figure 1) [147,148].

As mentioned previously, glucose may gain entry into the endothelial cells of the inner BRB only via transport mediated by GLUT1 [2]. Furthermore, GLUT1-mediated transport operates at near-saturation levels at normal physiological blood glucose concentrations [6]. Therefore, elevations in blood glucose levels, such as those seen in diabetes mellitus, will have only a minor impact in increasing intracellular glucose concentrations. Because GLUT1 represents a unique portal of entry of glucose into the endothelial cells of the inner BRB, changes in retinal endothelial cell GLUT1 expression and glucose transport may have a major impact in providing substrate to the various pathogenic processes thought to underlie the development of diabetic retinopathy (Figure 1).

In a previous study, Kumagai and co-workers used immunogold electron microscopy to demonstrate localized upregulation of GLUT1 in retinal endothelial cells of postmortem retina specimens from three individuals with long-standing diabetes but without clinical evidence of diabetic retinopathy (Figure 2) [135]. On the lumenal surface of the affected endothelia, there was a 20 -fold

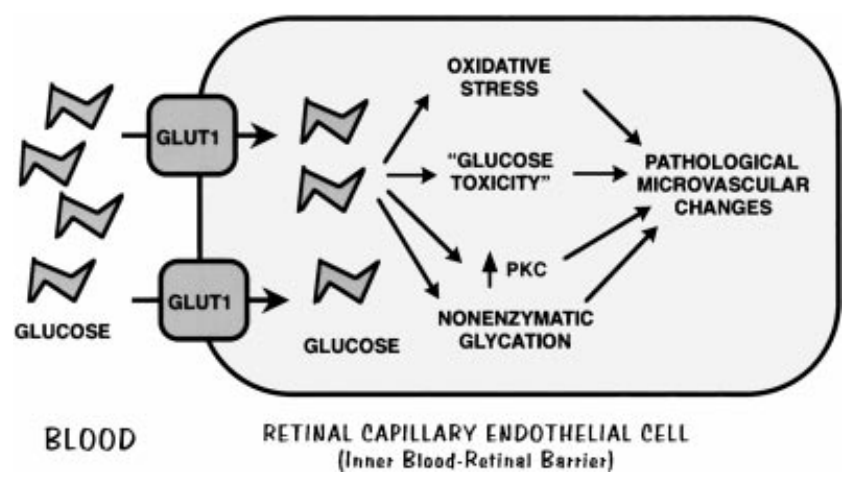

Figure 1. Proposed role of inner blood-retinal barrier GLUT1 in the development of microvascular pathology in diabetic retinopathy increase in immunoreactive GLUT1, compared to microvessel profiles from non-diabetic retinas [135]. The upregulation of inner BRB GLUT1 was not uniform in the diabetic microvessels, but appeared to be localized, i.e. only certain capillaries exhibited increased GLUT1 abundance, while in other microvessels, GLUT1 abundance was not significantly different from that seen in non-diabetic specimens. The focal nature of the changes in GLUT1 expression in the diabetic inner BRB observed in this study is reminiscent of the focal histopathological changes and areas of inner BRB compromise which occur in the retinal microvasculature in diabetic retinopathy $[143,149]$. Upregulation of total retinal GLUT1 mRNA has been reported in galactosemic rats, which develop hyperhexosemia and retinal lesions similar to those seen in human diabetic retinopathy [150], and GLUT1 mRNA abundance has been reported to be increased in the retina of streptozotocin-induced diabetic rats, albeit to a level which was not statistically significant [151]. Taken together, these studies suggest that upregulation of retinal and, in particular, inner BRB GLUT1 occurs in the early stages of diabetic retinopathy, and that the resultant increase in inner $\mathrm{BRB}$ glucose transport plays a role in the progression of the pathological changes seen in later stages of the disease.
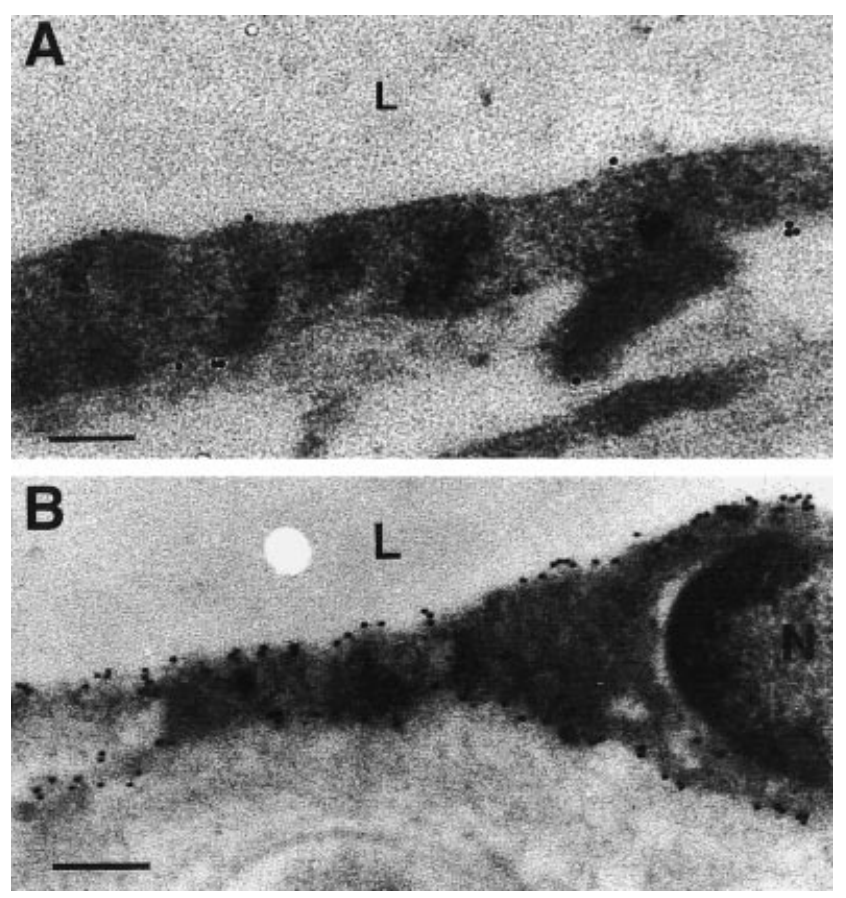

Figure 2. GLUT1 immunogold electron microscopy of nondiabetic and diabetic inner blood-retinal barrier. (A) Nondiabetic retinal endothelial cell labeled with a $1: 800$ dilution of anti-GLUT1 antiserum, followed by $10 \mathrm{~nm}$ colloid goldconjugated IgG. Sections were counterstained with uranyl acetate. GLUT1 immunogold is represented by discrete black dots along the lumenal or ablumenal membranes or scattered in the cytoplasm of the endothelial cell. Bar $=0.20 \mu \mathrm{m}$. (B) Representative endothelial cell from subpopulation of diabetic microvessels demonstrating dramatically increased GLUT1 expression. L, capillary lumen; N, nucleus of endothelial cell. Bar $=0.22 \mu \mathrm{m}$. Modified from Kumagai et al. [135]. Used with permission of Elsevier Science 
In order to understand the role which changes in inner BRB GLUT1 expression may play in the pathogenesis of diabetic retinopathy, studies of the effects of different factors associated with the development of diabetic retinopathy on inner BRB glucose transport and GLUT1 expression are needed. In a recent publication, Takagi and colleagues demonstrated upregulation of GLUT1 transcript and protein in primary cultures of bovine retinal endothelial cells exposed to hypoxia [140]. The hypoxic conditions $\left(0.5 \% \mathrm{O}_{2}\right)$ increased GLUT1 mRNA by approximately 9-fold and GLUT1 protein and 2-deoxyglucose transport by 2.5- and 3-fold, respectively, after $12 \mathrm{~h}$. These changes were partially mimicked by A2 adenosine receptor agonists and partially inhibited by A2 receptor antagonists. Furthermore, an inhibitor of protein kinase A (PKA) partially abolished the hypoxia-mediated increase in GLUT1 mRNA abundance. These experiments demonstrate that hypoxia can upregulate GLUT1 expression and glucose transport in vitro, and that this process occurs through an adenosine-A2 receptor-PKA pathway [140]. While hypoxia - a factor associated with advanced non-proliferative diabetic retinopathy - provides a potent stimulus for increases in GLUT1 expression in retinal endothelial cells [140], growth factors or other metabolic perturbations (e.g. oxidative stress, increased PKC activity) present early in the development of diabetic retinopathy may play a role in modulating inner BRB GLUT1. Studies from the author's laboratory have demonstrated an enhancement of glucose transport in primary bovine retinal endothelial cell cultures by vascular endothelial growth factor (VEGF) (A.K.K., in preparation). VEGF, a cytokine that selectively acts on endothelial cells to increase vascular permeability and stimulate angiogenesis [152], has been demonstrated to play a major role in the development of proliferative retinopathy [153-155]. Although there is some controversy [156], numerous studies in humans [157,158] and animal models [159,160] suggest that VEGF may play a role in the non-proliferative stage of the disease as well.

With regard to the direct effects of glucose on retinal vascular cell glucose transport, Mandarino and colleagues have reported that exposure to elevated glucose concentrations for 5 days downregulates both glucose transport and GLUT1 mRNA and protein in primary cultures of retinal pericytes, but has no effect on glucose transport retinal endothelial cells [141]. Changes in endothelial expression of GLUT1 transcript or protein were not investigated in this study. Knott and co-workers have reported upregulation of GLUT1 and GLUT3 mRNA in response to elevated glucose concentrations in human retinal endothelial cell cultures [161]. The observations of Knott and co-workers with respect to glucose-mediated changes in cultured retinal endothelial cell GLUT3 expression, however, are difficult to interpret, since immunoreactive GLUT3 is not detected in plasma membranes of cultured retinal endothelial cells [141], and more crucially, GLUT3 is not present in the retinal endothelial cells of the inner BRB in vivo [131].
A possible role of upregulated GLUT1 expression in the pathogenesis of diabetic complications is not unique for the retina. In a cell culture model of renal mesangial cells, another cell type which is selectively vulnerable to the effects of long-standing hyperglycemia, Heilig and coworkers induced mesangial cell GLUT1 overexpression via retroviral-mediated transfection. The investigators observed increased intracellular concentrations of sorbitol and myo-inositol and accumulation of extracellular matrix components in the GLUT1-overexpressing cultures grown in normal glucose when compared to lacZ transfected controls [162]. In other words, in mesangial cells in culture, overexpression of GLUT1 recapitulates at least some of the phenotypic characteristics of the diabetic milieu. While mesangial cells in culture differ from cultured retinal endothelium in that mesangial cell GLUT1 is positively regulated by glucose [163], factors associated with the diabetic milieu in the retina, such as localized hypoxia and growth factor expression, may serve as the initial impetus for GLUT1 upregulation and thus expose the endothelial cells of the retina to elevated intracellular glucose concentrations. In this manner, localized upregulation of inner BRB GLUT1 expression may exacerbate the deleterious effects of hyperglycemia on the retinal microvasculature and play a critical role in the development and progression of diabetic retinopathy.

\section{Conclusions}

Facilitated transport of glucose across the continuous endothelium comprising the BBB and inner BRB ensures continual delivery of this essential metabolite into the brain and retina, respectively. As described above, this transport process, and the glucose transporter that mediates it, may be modulated by a variety of factors, including hypoxia, growth factors, physiologic stress and glucose itself. Changes in endothelial glucose transport and in the abundance of GLUT1 on the endothelial plasma membrane in these barriers may have profound consequences in glucose delivery to neural tissue and may be intimately connected with the development of complications associated with diabetes mellitus and its treatment. In the brain, hypoglycemia-associated compensatory upregulation of $\mathrm{BBB}$ glucose transport may preserve $\mathrm{BBB}$ glucose transport and brain glucose metabolism in the face of low peripheral blood glucose concentrations. The ultimate consequence of this increase, however, may be deleterious: changes in brain glucose transport in the setting of intensive insulin therapy may result in a blunting of the counterregulatory response to hypoglycemia, a decreased awareness of autonomic warning symptoms, and a substantially increased risk of further, more severe hypoglycemic episodes. In the retina, increased abundance of GLUT1 on the plasma membranes of retinal capillary endothelial cells resulting from exposure to various factors associated with the development of diabetic retinopathy (e.g. hypoxia, growth factors) may lead to increased glucose 
transport into the endothelial cells (Figure 1). This increased influx, and the subsequent increase in intracellular glucose concentrations, may exacerbate the effects of hyperglycemia on the endothelial cell, in effect by 'adding fuel to the fire' of the various biochemical and molecular processes leading to the development of the characteristic structural and functional changes in the inner BRB associated with diabetic retinopathy. The studies described above suggest the critical importance of BBB glucose transport to changes in brain glucose sensing and to the increased risk of severe hypoglycemia experienced by individuals attempting to achieve optimal glycemic control. With regards to diabetic retinopathy, a paradigm is proposed in which changes in glucose transport in the endothelia of the inner BRB participate in the development of the microvascular lesions in the retina in long-standing diabetes mellitus. Clarification of the exact role of changes in $\mathrm{BBB}$ and inner BRB glucose transport and glucose transporter expression, and the molecular processes underlying such changes, in these complications of diabetes are the subject of ongoing investigation.

\section{Acknowledgements}

The author would like to thank Drs Hirohito Sone and ChardpraOrn Ngarmukos and Ms Baljeet Deo for their efforts in many of these studies, and Drs Frank C. Brosius III, Rubén Boado, Christin Carter-Su, Douglas A. Greene and William M. Pardridge for many valuable discussions. This work was supported by National Institutes of Health grant EY000369 and grants from the Juvenile Diabetes Foundation and the American Diabetes Association. This work was also supported in part by National Institutes of Health grant 5PO60DK-20572, which supports the Michigan Diabetes Research and Training Center.

\section{References}

1. Lund-Andersen H. Transport of glucose from blood to brain. Physiol Rev 1979; 59: 305-352.

2. Takata K, Hirano H, Kasahara M. Transport of glucose across the blood-tissue barriers. Int Rev Cytol 1997; 172: 1-53.

3. Pardridge WM, Oldendorf WH, Cancilla P, Frank HJ. Bloodbrain barrier: interface between internal medicine and the brain [clinical conference]. Ann Int Med 1986; 105: 82-95.

4. Cunha-Vaz JG. The blood-retinal barriers. Doc Ophthalmol 1976; 41: 287-327.

5. Bell GI, Kayano T, Buse JB, et al. Molecular biology of mammalian glucose transporters. Diabetes Care 1990; 13: 198-208.

6. Mueckler M. Facilitative glucose transporters. Eur J Biochem 1994; 219: 713-725.

7. Mueckler M, Caruso C, Baldwin SA, Panico M, Blench I, Morris $\mathrm{HR}$, Allard WJ, Lienhard GE, Lodish HF. Sequence and structure of a human glucose transporter. Science 1985; 229: 941-945.

8. Harik SI, Kalaria RN, Whitney PM, et al. Glucose transporters are abundant in cells with 'occluding' junctions at the bloodeye barriers. Proc Natl Acad Sci U S A 1990; 87: 4261-4264.

9. Takata K, Kasahara T, Kasahara M, Ezaki O, Hirano H. Erythrocyte/HepG2-type glucose transporter is concentrated in cells of blood-tissue barriers. Biochem Biophys Res Commun 1990; 173: 67-73.

10. Thorens B, Sarkar HK, Kaback HR, Lodish HF. Cloning and functional expression in bacteria of a novel glucose transporter present in liver, intestine, kidney, and beta-pancreatic islet cells. Cell 1988; 55: 281-290.

11. Kayano T, Fukumoto H, Eddy RL, et al. Evidence for a family of human glucose transporter-like proteins. Sequence and gene localization of a protein expressed in fetal skeletal muscle and other tissues. J Biol Chem 1988; 263: 15245-15248.

12. Nagamatsu S, Kornhauser JM, Burant CF, Seino S, Mayo KE, Bell GI. Glucose transporter expression in brain. cDNA sequence of mouse GLUT3, the brain facilitative glucose transporter isoform, and identification of sites of expression by in situ hybridization. $J$ Biol Chem 1992; 267: 467-472.

13. James DE, Strube M, Mueckler M. Molecular cloning and characterization of an insulin-regulatable glucose transporter. Nature 1989; 338: 83-87.

14. Charron MJ, Brosius FC 3rd, Alper SL, Lodish HF. A glucose transport protein expressed predominately in insulinresponsive tissues. Proc Natl Acad Sci USA 1989; 86: 2535-2539.

15. Kayano T, Burant CF, Fukumoto $\mathrm{H}$, et al. Human facilitative glucose transporters. Isolation, functional characterization, and gene localization of cDNAs encoding an isoform (GLUT5) expressed in small intestine, kidney, muscle, and adipose tissue and an unusual glucose transporter pseudogene-like sequence (GLUT6). J Biol Chem 1990; 265: 13276-13282.

16. Boado RJ, Pardridge WM. Molecular cloning of the bovine blood-brain barrier glucose transporter cDNA and demonstration of phylogenetic conservation of the 5 '-untranslated region. Mol Cell Neurosci 1990; 1: 224-232.

17. Baldwin SA, Lienhard GE. Purification and reconstitution of glucose transporter from human erythrocytes. Methods Enzymol 1989; 174: 39-50.

18. Asano T, Katagiri H, Takata $\mathrm{K}$, et al. The role of $\mathrm{N}$-glycosylation of GLUT1 for glucose transport activity. J Biol Chem 1991; 266: 24632-24636.

19. Kumagai AK, Dwyer KJ, Pardridge WM. Differential glycosylation of the GLUT1 glucose transporter in brain capillaries and choroid plexus. Biochim Biophys Acta 1994; 1193: 24-30.

20. Vera JC, Rivas CI, Fischbarg J, Golde DW. Mammalian facilitative hexose transporters mediate the transport of dehydroascorbic acid. Nature 1993; 364: 79-82.

21. Agus DB, Gambhir SS, Pardridge WM, et al. Vitamin C crosses the blood-brain barrier in the oxidized form through the glucose transporters. J Clin Invest 1997; 100: 2842-2848.

22. Pardridge WM, Boado RJ. Molecular cloning and gene expression of blood-brain barrier glucose transporter. In The Blood-Brain Barrier: Cellular and Molecular Biology, Pardridge WM (ed). New York: Raven Press, 1993; 395-440.

23. Maher F, Vannucci SJ, Simpson IA. Glucose transporter proteins in brain. FASEB $J$ 1994; 8: 1003-1011.

24. Pardridge WM, Boado RJ, Farrell CR. Brain-type glucose transporter (GLUT-1) is selectively localized to the blood-brain barrier. Studies with quantitative western blotting and in situ hybridization. J Biol Chem 1990; 265: 18035-18040.

25. Boado RJ, Pardridge WM. The brain-type glucose transporter mRNA is specifically expressed at the blood-brain barrier. Biochem Biophys Res Commun 1990; 166: 174-179.

26. Kumagai AK, Kang YS, Boado RJ, Pardridge WM. Upregulation of GLUT1 glucose transporter mRNA and protein in experimental chronic hypoglycemia. Diabetes 1995; 44: 1399-1404.

27. Maher F, Vannucci SJ, Simpson IA. Glucose transporter isoforms in brain: absence of GLUT3 from the blood-brain barrier. J Cereb Blood Flow Metab 1993; 13: 342-345.

28. Bondy CA, Lee WH, Zhou J. Ontogeny and cellular distribution of brain glucose transporter gene expression. Mol Cell Neurosci 1992; 3: 305-314.

29. McCall AL, van Bueren AM, Nipper V, Moholt-Siebert M, Downes H, Lessov N. Forebrain ischemia increases GLUT1 protein in brain microvessels and parenchyma. $J$ Cereb Blood Flow Metab 1996; 16: 69-76.

30. Yu S, Ding WG. The $45 \mathrm{kDa}$ form of glucose transporter 1 (GLUT1) is localized in oligodendrocyte and astrocyte but not in microglia in the rat brain. Brain Res 1998; 797: 65-72.

31. Walker PS, Donovan JA, van Ness BG, Fellows RE, Pessin JE Glucose-dependent regulation of glucose transport activity, protein, and mRNA in primary cultures of rat brain glial cells. J Biol Chem 1988; 263: 15594-15601.

32. Dick AP, Harik SI, Klip A, Walker DM. Identification and characterization of the glucose transporter of the blood-brain 
barrier by cytochalasin B binding and immunological reactivity. Proc Natl Acad Sci U S A 1984; 81: 7233-7237.

33. Farrell CL, Pardridge WM. Blood-brain barrier glucose transporter is asymmetrically distributed on brain capillary endothelial lumenal and ablumenal membranes: an electron microscopic immunogold study. Proc Natl Acad Sci U S A 1991; 88: 5779-5783.

34. Cornford EM, Hyman S, Pardridge WM. An electron microscopic immunogold analysis of developmental up-regulation of the blood-brain barrier GLUT1 glucose transporter. $J$ Cereb Blood Flow Metab 1993; 13: 841-854.

35. Gerhart DZ, Broderius MA, Borson ND, Drewes LR. Neurons and microvessels express the brain glucose transporter protein GLUT3. Proc Natl Acad Sci U S A 1992; 89: 733-737.

36. Mantych GJ, James DE, Chung HD, Devaskar SU. Cellular localization and characterization of Glut 3 glucose transporter isoform in human brain. Endocrinology 1992; 131: 1270-1278.

37. Nagamatsu S, Sawa H, Kamada K, Nakamichi Y, Yoshimoto K, Hoshino T. Neuron-specific glucose transporter (NSGT): CNS distribution of GLUT3 rat glucose transporter (RGT3) in rat central neurons. FEBS Lett 1993; 334: 289-295.

38. Jetton TL, Liang Y, Pettepher CC, et al. Analysis of upstream glucokinase promoter activity in transgenic mice and identification of glucokinase in rare neuroendocrine cells in the brain and gut. J Biol Chem 1994; 269: 3641-3654.

39. McCall AL, van Bueren AM, Huang L, Stenbit A, Celnik E, Charron MJ. Forebrain endothelium expresses GLUT4, the insulin-responsive glucose transporter. Brain Res 1997; 744: 318-326.

40. Mantych GJ, James DE, Devaskar SU. Jejunal/kidney glucose transporter isoform (Glut-5) is expressed in the human blood-brain barrier. Endocrinology 1993; 132: 35-40.

41. Nishizaki T, Kammesheidt A, Sumikawa K, Asada T, Okada Y. A sodium- and energy-dependent glucose transporter with similarities to SGLT1-2 is expressed in bovine cortical vessels. Neurosci Res 1995; 22: 13-22.

42. Dwyer KJ, Pardridge WM. Developmental modulation of blood-brain barrier and choroid plexus GLUT1 glucose transporter messenger ribonucleic acid and immunoreactive protein in rabbits. Endocrinology 1993; 132: 558-565.

43. Pardridge WM, Oldendorf WH. Kinetics of blood-brain transport of hexoses. Biochim Biophys Acta 1975; 382: 377-392.

44. McCall AL, Millington WR, Wurtman RJ. Metabolic fuel and amino acid transport into the brain in experimental diabetes mellitus. Proc Natl Acad Sci U S A 1982; 79: 5406-5410.

45. Pardridge WM, Triguero D, Farrell CR. Downregulation of blood-brain barrier glucose transporter in experimental diabetes. Diabetes 1990; 39: 1040-1044.

46. Boyle PJ, Kempers SF, O'Connor AM, Nagy RJ. Brain glucose uptake and unawareness of hypoglycemia in patients with insulin-dependent diabetes mellitus. N Engl J Med 1995; 333: $1726-1731$.

47. Sokoloff L, Reivich M, Kennedy C, et al. The [14C]deoxyglucose method for the measurement of local cerebral glucose utilization: theory, procedure, and normal values in the conscious and anesthetized albino rat. J Neurochem 1977; 28: 897-916.

48. Pardridge WM, Crane PD, Mietus LJ, Oldendorf WH. Kinetics of regional blood-brain barrier transport and brain phosphorylation of glucose and 2-deoxyglucose the barbiturate-anesthetized rat. $J$ Neurochem 1982; 38: 560-568.

49. Hawkins RA, Mans AM, Davis DW, Hibbard LS, Lu DM. Glucose availability to individual cerebral structures is correlated to glucose metabolism. $J$ Neurochem 1983; 40: 1013-1018.

50. Pelligrino DA, Segil LJ, Albrecht RF. Brain glucose utilization and transport and cortical function in chronic vs. acute hypoglycemia. Am J Physiol 1990; 259: E729-E735.

51. Brant AM, Jess TJ, Milligan G, Brown CM, Gould GW. Immunological analysis of glucose transporters expressed in different regions of the rat brain and central nervous system. Biochem Biophys Res Commun 1993; 192: 1297-1302.

52. Zeller K, Rahner-Welsch S, Kuschinsky W. Distribution of Glut1 glucose transporters in different brain structures compared to glucose utilization and capillary density of adult rat brains. J Cereb Blood Flow Metab 1997; 17: 204-209.

53. Zeller K, Duelli R, Vogel J, Schrock H, Kuschinsky W. Autoradiographic analysis of the regional distribution of
Glut3 glucose transporters in the rat brain. Brain Res 1995; 698: 175-179.

54. Sivitz W, DeSautel S, Walker PS, Pessin JE. Regulation of the glucose transporter in developing rat brain. Endocrinology 1989; 124: 1875-1880.

55. Devaskar S, Zahm DS, Holtzclaw L, Chundu K, Wadzinski BE. Developmental regulation of the distribution of rat brain insulin-insensitive (Glut 1) glucose transporter. Endocrinology 1991; 129: 1530-1540.

56. Dermietzel R, Krause D, Kremer M, Wang C, Stevenson B. Pattern of glucose transporter (Glut 1) expression in embryonic brains is related to maturation of blood-brain barrier tightness. Dev Dynamics 1992; 193: 152-163.

57. Vannucci SJ. Developmental expression of GLUT1 and GLUT3 glucose transporters in rat brain. $J$ Neurochem 1994; 62: 240-246.

58. Boado RJ, Pardridge WM. A one-step procedure for isolation of poly(A) + mRNA from isolated brain capillaries and endothelial cells in culture. J Neurochem 1991; 57: 2136-2139.

59. Boado RJ, Pardridge WM. Glucose deprivation causes posttranscriptional enhancement of brain capillary endothelial glucose transporter gene expression via GLUT1 mRNA stabilization. J Neurochem 1993; 60: 2290-2296.

60. Farrell CR, Boado RJ, Pardridge WM. Enhanced GLUT1 glucose transporter and cytoskeleton gene expression in cultured bovine brain capillary endothelial cells after treatment with phorbol esters and serum. Brain Res Mol Brain Res 1992; 15: 221-226.

61. Boado RJ, Pardridge WM. Measurement of blood-brain barrier GLUT1 glucose transporter and actin mRNA by a quantitative polymerase chain reaction assay. $J$ Neurochem 1994; 62: 2085-2090.

62. Boado RJ, Wang L, Pardridge WM. Enhanced expression of the blood-brain barrier GLUT1 glucose transporter gene by brainderived factors. Brain Res Mol Brain Res 1994; 22: 259-267.

63. Estrada C, Bready JV, Berliner JA, Pardridge WM, Cancilla PA. Astrocyte growth stimulation by a soluble factor produced by cerebral endothelial cells in vitro. $J$ Neuropathol Exp Neurol 1990; 49: 539-549.

64. Takakura Y, Trammel AM, Kuentzel SL, et al. Hexose uptake in primary cultures of bovine brain microvessel endothelial cells. II. Effects of conditioned media from astroglial and glioma cells. Biochim Biophys Acta 1991; 1070: 11-19.

65. Takakura Y, Kuentzel SL, Raub TJ, Davies A, Baldwin SA, Borchardt RT. Hexose uptake in primary cultures of bovine brain microvessel endothelial cells. I. Basic characteristics and effects of D-glucose and insulin. Biochim Biophys Acta 1991; 1070: $1-10$.

66. Gjedde A, Crone C. Blood-brain glucose transfer: repression in chronic hyperglycemia. Science 1981; 214: 456-457.

67. McCall AL, Fixman LB, Fleming N, Tornheim K, Chick W, Ruderman NB. Chronic hypoglycemia increases brain glucose transport. Am J Physiol 1986; 251: E442-E447.

68. Koranyi L, Bourey RE, James D, Mueckler M, Fidorek FT Jr, Premutt MA. Glucose transporter gene expression in rat brain: pretranslational changes associated with chronic insulininduced hypoglycemia, fasting and diabetes. Mol Cell Neurosci 1991; 2: 244-252.

69. Simpson IA, Appel NM, Hotari M, et al. Blood-brain barrier glucose transporter: effects of hypo- and hyperglycemia revisited. J Neurochem 1999; 72: 238-247.

70. Lee WH, Bondy CA. Ischemic injury induces brain glucose transporter gene expression. Endocrinology 1993; 133: 2540-2544.

71. Gerhart DZ, Leino RL, Taylor WE, Borson ND, Drewes LR. GLUT1 and GLUT3 gene expression in gerbil brain following brief ischemia: an in situ hybridization study. Brain Res Mol Brain Res 1994; 25: 313-322.

72. Vannucci SJ, Reinhart R, Maher F, et al. Alterations in GLUT1 and GLUT3 glucose transporter gene expression following unilateral hypoxia-ischemia in the immature rat brain. Brain Res Dev Brain Res 1998; 107: 255-264.

73. Cornford EM, Hyman S, Swartz BE. The human brain GLUT1 glucose transporter: ultrastructural localization to the bloodbrain barrier endothelia. J Cereb Blood Flow Metab 1994; 14: 106-112.

74. Gronlund KM, Gerhart DZ, Leino RL, McCall AL, Drewes LR. 
Chronic seizures increase glucose transporter abundance in rat brain. J Neuropathol Exp Neurol 1996; 55: 832-840.

75. Kalaria RN, Harik SI. Reduced glucose transporter at the blood-brain barrier and in cerebral cortex in Alzheimer disease. J Neurochem 1989; 53: 1083-1088.

76. Gamberino WC, Brennan WA Jr. Glucose transporter isoform expression in Huntington's disease brain. J Neurochem 1994; 63: 1392-1397.

77. Nagamatsu S, Sawa H, Wakizaka A, Hoshino T. Expression of facilitative glucose transporter isoforms in human brain tumors. J Neurochem 1993; 61: 2048-2053.

78. Boado RJ, Black KL, Pardridge WM. Gene expression of GLUT3 and GLUT1 glucose transporters in human brain tumors. Brain Res Mol Brain Res 1994; 27: 51-57.

79. Tsukamoto H, Boado RJ, Pardridge WM. Differential expression in glioblastoma multiforme and cerebral hemangioblastoma of cytoplasmic proteins that bind two different domains within the $3^{\prime}$-untranslated region of the human glucose transporter 1 (GLUT1) messenger RNA. $J$ Clin Invest 1996; 97: 2823-2832.

80. Ho DY, Saydam TC, Fink SL, Lawrence MS, Sapolsky RM. Defective herpes simplex virus vectors expressing the rat brain glucose transporter protect cultured neurons from necrotic insults. J Neurochem 1995; 65: 842-850.

81. Lawrence MS, Sun GH, Kunis DM, et al. Overexpression of the glucose transporter gene with a herpes simplex viral vector protects striatal neurons against stroke. $J$ Cereb Blood Flow Metab 1996; 16: 181-185.

82. Seidner G, Alvarez MG, Yeh JI, et al. GLUT-1 deficiency syndrome caused by haploinsufficiency of the blood-brain barrier hexose carrier. Nat Genet 1998; 18: 188-191.

83. Cornford EM, Hyman S, Cornford ME, Clare-Salzler M. Downregulation of blood-brain glucose transport in the hyperglycemic nonobese diabetic mouse. Neurochem Res 1995; 20 869-873.

84. Matthaei S, Horuk R, Olefsky JM. Blood-brain glucose transfer in diabetes mellitus. Decreased number of glucose transporters at blood-brain barrier. Diabetes 1986; 35: 1181-1184.

85. Lilavivathana U, Brodows RG, Woolf PD, Campbell RG. Counterregulatory hormonal responses to rapid glucose lowering in diabetic man. Diabetes 1979; 28: 873-877.

86. DeFronzo RA, Hendler R, Christensen N. Stimulation of counterregulatory hormonal responses in diabetic man by a fall in glucose concentration. Diabetes 1980; 29: 125-131.

87. Boyle PJ, Schwartz NS, Shah SD, Clutter WE, Cryer PE. Plasma glucose concentrations at the onset of hypoglycemic symptoms in patients with poorly controlled diabetes and in nondiabetics. N Engl J Med 1988; 318: 1487-1492.

88. Duckrow RB. Glucose transfer into rat brain during acute and chronic hyperglycemia. Metab Brain Dis 1988; 3: 201-209.

89. Harik SI, LaManna JC. Vascular perfusion and blood-brain glucose transport in acute and chronic hyperglycemia. J Neurochem 1988; 51: 1924-1929.

90. Mooradian AD, Morin AM. Brain uptake of glucose in diabetes mellitus: the role of glucose transporters. Am J Med Sci 1991; 301: 173-177.

91. Pelligrino DA, Lipa MD, Albrecht RF. Regional blood-brain glucose transfer and glucose utilization in chronically hyperglycemic, diabetic rats following acute glycemic normalization. J Cereb Blood Flow Metab 1990; 10: 774-780.

92. Fanelli CG, Dence CS, Markham J, et al. Blood-to-brain glucose transport and cerebral glucose metabolism are not reduced in poorly controlled type 1 diabetes. Diabetes 1998; 47: 1444-1450.

93. Pelligrino DA, LaManna JC, Duckrow RB, Bryan RM Jr, Harik SI. Hyperglycemia and blood-brain barrier glucose transport. J Cereb Blood Flow Metab 1992; 12: 887-899.

94. Choi TB, Boado RJ, Pardridge WM. Blood-brain barrier glucose transporter mRNA is increased in experimental diabetes mellitus. Biochem Biophys Res Commun 1989; 164: 375-380.

95. Anon. The effect of intensive treatment of diabetes on the development and progression of long-term complications in insulin-dependent diabetes mellitus. The Diabetes Control and Complications Trial Research Group. N Engl J Med 1993; 329: 977-986.

96. DCCT. Epidemiology of severe hypoglycemia in the diabetes control and complications trial. The DCCT Research Group. Am J Med 1991; 90: 450-459.
97. Cryer PE. Banting lecture. Hypoglycemia: the limiting factor in the management of IDDM. Diabetes 1994; 43: 1378-1389.

98. Kleinbaum J, Shamoon H. Impaired counterregulation of hypoglycemia in insulin-dependent diabetes mellitus. Diabetes 1983; 32: 493-498.

99. Amiel SA, Tamborlane WV, Simonson DC, Sherwin RS. Defective glucose counterregulation after strict glycemic control of insulin-dependent diabetes mellitus. $N$ Engl $J$ Med 1987; 316: 1376-1383.

100. Amiel SA, Sherwin RS, Simonson DC, Tamborlane WV. Effect of intensive insulin therapy on glycemic thresholds for counterregulatory hormone release. Diabetes 1988; 37: 901907.

101. Davis MR, Mellman M, Shamoon H. Further defects in counterregulatory responses induced by recurrent hypoglycemia in IDDM. Diabetes 1992; 41: 1335-1340.

102. Cryer PE. Hypoglycemia in diabetes mellitus. In Hypoglycemia: Pathophysiology, Diagnosis and Treatment. Oxford: OUP, 1997; 91-126.

103. Mitrakou A, Ryan C, Veneman T, et al. Hierarchy of glycemic thresholds for counterregulatory hormone secretion, symptoms, and cerebral dysfunction. Am J Physiol 1991; 260: E67-E74.

104. Boyle PJ, Shah SD, Cryer PE. Insulin, glucagon, and catecholamines in prevention of hypoglycemia during fasting. Am J Physiol 1989; 256: E651-E661.

105. Gerich JE, Langlois M, Noacco C, Karam JH, Forsham PH. Lack of glucagon response to hypoglycemia in diabetes: evidence for an intrinsic pancreatic alpha cell defect. Science 1973; 182: 171-173.

106. Bolli G, Calabrese G, De Feo P, et al. Lack of glucagon response in glucose counter-regulation in type 1 (insulin-dependent) diabetics: absence of recovery after prolonged optimal insulin therapy. Diabetologia 1982; 22: 100-105.

107. Amiel SA. Hypoglycaemia in diabetes mellitus - protecting the brain. Diabetologia 1997; 40: S62-S68.

108. Simonson DC, Tamborlane WV, DeFronzo RA, Sherwin RS Intensive insulin therapy reduces counterregulatory hormone responses to hypoglycemia in patients with type I diabetes. Ann Int Med 1985; 103: 184-190.

109. Widom B, Simonson DC. Intermittent hypoglycemia impairs glucose counterregulation. Diabetes 1992; 41: 1597-1602.

110. Perriello G, De Feo P, Torlone E, et al. The effect of asymptomatic nocturnal hypoglycemia on glycemic control in diabetes mellitus. $N$ Engl $J$ Med 1988; 319: 1233-1239.

111. Cryer PE. Hypoglycemia begets hypoglycemia in IDDM. Diabetes 1993; 42: 1691-1693.

112. Gold AE, MacLeod KM, Frier BM. Frequency of severe hypoglycemia in patients with type I diabetes with impaired awareness of hypoglycemia. Diabetes Care 1994; 17: 697-703.

113. Langan SJ, Deary IJ, Hepburn DA, Frier BM. Cumulative cognitive impairment following recurrent severe hypoglycaemia in adult patients with insulin-treated diabetes mellitus. Diabetologia 1991; 34: 337-344.

114. Crane PD, Pardridge WM, Braun LD, Nyerges AM, Oldendorf WH. The interaction of transport and metabolism on brain glucose utilization: a reevaluation of the lumped constant. J Neurochem 1981; 36: 1601-1604.

115. Biggers DW, Myers SR, Neal D, et al. Role of brain in counterregulation of insulin-induced hypoglycemia in dogs. Diabetes 1989; 38: 7-16.

116. Borg WP, Sherwin RS, During MJ, Borg MA, Shulman GI. Local ventromedial hypothalamus glucopenia triggers counterregulatory hormone release. Diabetes 1995; 44: 180-184.

117. Borg MA, Sherwin RS, Borg WP, Tamborlane WV, Shulman GI Local ventromedial hypothalamus glucose perfusion blocks counterregulation during systemic hypoglycemia in awake rats. $J$ Clin Invest 1997; 99: 361-365.

118. Hamilton-Wessler M, Bergman RN, Halter JB, Watanabe RM, Donovan CM. The role of liver glucosensors in the integrated sympathetic response induced by deep hypoglycemia in dogs. Diabetes 1994; 43: 1052-1060.

119. Donovan CM, Halter JB, Bergman RN. Importance of hepatic glucoreceptors in sympathoadrenal response to hypoglycemia. Diabetes 1991; 40: 155-158.

120. Leloup C, Arluison M, Lepetit N, et al. Glucose transporter 2 (GLUT 2): expression in specific brain nuclei. Brain Res 1994; 638: $221-226$ 
121. Navarro M, Rodriquez de Fonseca F, Alvarez E, et al. Colocalization of glucagon-like peptide-1 (GLP-1) receptors, glucose transporter GLUT-2, and glucokinase mRNAs in rat hypothalamic cells: evidence for a role of GLP-1 receptor agonists as an inhibitory signal for food and water intake. J Neurochem 1996; 67: 1982-1991.

122. Lucignani G, Namba H, Nehlig A, Porrino LJ, Kennedy C, Sokoloff L. Effects of insulin on local cerebral glucose utilization in the rat. $J$ Cereb Blood Flow Metab 1987; 7: 309-314.

123. Graymore C. Biochemistry of the Retina. In Biochemistry of the Eye, Graymore C (ed). London: Academic Press, 1970; 645-675.

124. Alm A, Tornquist P, Maepea O. The uptake index method applied to studies on the blood-retinal barrier. II. Transport of several hexoses by a common carrier. Acta Physiol Scand 1981; 113: 81-84.

125. Ennis SR, Johnson JE, Pautler EL. In situ kinetics of glucose transport across the blood-retinal barrier in normal rats and rats with streptozocin-induced diabetes. Invest Ophthalmol Vis Sci 1982; 23: 447-456.

126. Alm A. Kinetics of glucose transport across the blood-retinal barrier [letter]. Invest Ophthalmol Vis Sci 1984; 25: 491-493.

127. Betz AL, Goldstein GW. Transport of hexoses, potassium and neutral amino acids into capillaries isolated from bovine retina. Exp Eye Res 1980; 30: 593-605.

128. Berkowitz BA, Garner MH, Wilson CA, Corbett RJ. Nondestructive measurement of retinal glucose transport and consumption in vivo using NMR spectroscopy. J Neurochem 1995 64: 2325-2331.

129. Stramm LE, Pautler EL. Transport of 3-O-methylglucose in isolated rat retinal pigment epithelial cells. Exp Eye Res 1982; 35: 91-97.

130. DiMattio J, Streitman J. Facilitated glucose transport across the retinal pigment epithelium of the bullfrog (Rana catesbeiana). Exp Eye Res 1986; 43: 15-28.

131. Mantych GJ, Hageman GS, Devaskar SU. Characterization of glucose transporter isoforms in the adult and developing human eye. Endocrinology 1993; 133: 600-607.

132. Kumagai AK, Glasgow BJ, Pardridge WM. GLUT1 glucose transporter expression in the human diabetic and nondiabetic eye. Invest Ophthalmol Vis Sci 1994; 35: 2887-2889.

133. Kumagai AK, Glasgow BJ, Pardridge WM. GLUT1 glucose transporter expression in the diabetic and nondiabetic human eye. Invest Ophthalmol Vis Sci 1994; 35: 2887-2894.

134. Takata K, Kasahara T, Kasahara M, Ezaki O, Hirano H. Ultracytochemical localization of the erythrocyte/HepG2-type glucose transporter (GLUT1) in cells of the blood-retina barrier in the rat. Invest Ophthalmol Vis Sci 1992; 33: 377-383.

135. Kumagai AK, Vinores SA, Pardridge WM. Pathological upregulation of inner blood-retinal barrier GLUT1 glucose transporter expression in diabetes mellitus. Brain Res 1996; 706: 313-317.

136. Poitry-Yamate CL, Tsacopoulos M. Glucose metabolism in freshly isolated Muller glial cells from a mammalian retina. J Comp Neuro 1992; 320: 257-266.

137. Kuwabara T, Cogan DG. Retinal glycogen. Arch Ophthalmol 1961; 66: 680-688.

138. Tsacopoulos M, Poitry-Yamate CL, Poitry S, Perrottet P Veuthey AL. The nutritive function of glia is regulated by signals released by neurons. Glia 1997; 21: 84-91.

139. Watanabe T, Mio Y, Hoshino FB, Nagamatsu S, Hirosawa K, Nakahara K. GLUT2 expression in the rat retina: localization at the apical ends of Muller cells. Brain Res 1994; 655: 128-134.

140. Takagi H, King GL, Aiello LP. Hypoxia upregulates glucose transport activity through an adenosine-mediated increase of GLUT1 expression in retinal capillary endothelial cells. Diabetes 1998; 47: 1480-1488.

141. Mandarino LJ, Finlayson J, Hassell JR. High glucose downregulates glucose transport activity in retinal capillary pericytes but not endothelial cells. Invest Ophthalmol Vis Sci 1994; 35 964-972.

142. Takagi $\mathrm{H}$, Tanihara $\mathrm{H}$, Seino $\mathrm{Y}$, Yoshimura N. Characterization of glucose transporter in cultured human retinal pigment epithelial cells: gene expression and effect of growth factors Invest Ophthalmol Vis Sci 1994; 35: 170-177.
143. Ferris FLd. Diabetic retinopathy. Diabetes Care 1993; 16: 322-325.

144. Aiello LP, Gardner TW, King GL, Blankenship G, Cavallerano JD, Ferris FL, Klein R. Diabetic retinopathy. Diabetes Care 1998; 21: 143-156.

145. Klein R. Hyperglycemia and microvascular and macrovascular disease in diabetes. Diabetes Care 1995; 18: 258-268.

146. King GL, Kunisaki M, Nishio Y, Inoguchi T, Shiba T, Xia P. Biochemical and molecular mechanisms in the development of diabetic vascular complications. Diabetes 1996; 45: S105S108.

147. Lorenzi M. Glucose toxicity in the vascular complications of diabetes: the cellular perspective. Diabetes Metab Rev 1992; 8: 85-103.

148. King GL, Brownlee M. The cellular and molecular mechanisms of diabetic complications. Endocrinol Metab Clin North Am 1996; 25: 255-270.

149. Vinores SA, Van Niel E, Swerdloff JL, Campochiaro PA. Electron microscopic immunocytochemical demonstration of blood-retinal barrier breakdown in human diabetics and its association with aldose reductase in retinal vascular endothelium and retinal pigment epithelium. Histochem $J$ 1993; 25 : 648-663.

150. Roy S. Distribution and expression of GLUT1 in the retina of the galactose-fed rat. [ARVO Abstract]. Invest Ophthalmol Vis Sci 1996; 37: S970.

151. Poulsom R, Prockop DJ, Boot-Handford RP. Effects of longterm diabetes and galactosaemia upon lens and retinal mRNA levels in the rat. Exp Eye Res 1990; 51: 27-32.

152. Ferrara N, Davis-Smyth T. The biology of vascular endothelial growth factor. Endocr Rev 1997; 18: 4-25.

153. Adamis AP, Miller JW, Bernal MT, et al. Increased vascular endothelial growth factor levels in the vitreous of eyes with proliferative diabetic retinopathy. Am J Ophthalmol 1994; 118: 445-450.

154. Aiello LP, Avery RL, Arrigg PG, et al. Vascular endothelial growth factor in ocular fluid of patients with diabetic retinopathy and other retinal disorders. N Engl J Med 1994; 331: 1480-1487.

155. Pe'er J, Folberg R, Itin A, Gnessin H, Hemo I, Keshet E. Upregulated expression of vascular endothelial growth factor in proliferative diabetic retinopathy. Br J Ophthalmol 1996; 80: 241-245.

156. Gerhardinger C, Brown LF, Roy S, Mizutani M, Zucker CL, Lorenzi M. Expression of vascular endothelial growth factor in the human retina and in nonproliferative diabetic retinopathy. Am J Pathol 1998; 152: 1453-1462.

157. Lutty GA, McLeod DS, Merges C, Diggs A, Plouet J. Localization of vascular endothelial growth factor in human retina and choroid. Arch Ophthalmol 1996; 114: 971-977.

158. Amin RH, Frank RN, Kennedy A, Eliott D, Puklin JE, Abrams GW. Vascular endothelial growth factor is present in glial cells of the retina and optic nerve of human subjects with nonproliferative diabetic retinopathy. Invest Ophthalmol Vis Sci 1997; 38: 36-47.

159. Murata $\mathrm{T}$, Nakagawa $\mathrm{K}$, Khalil A, Ishibashi $\mathrm{T}$, Inomata $\mathrm{H}$ Sueishi K. The relation between expression of vascular endothelial growth factor and breakdown of the blood-retinal barrier in diabetic rat retinas. Lab Invest 1996; 74: 819-825.

160. Sone H, Kawakami Y, Okuda Y, et al. Ocular vascular endothelial growth factor levels in diabetic rats are elevated before observable retinal proliferative changes. Diabetologia 1997; 40: 726-730.

161. Knott RM, Robertson M, Muckersie E, Forrester JV. Regulation of glucose transporters (GLUT-1 and GLUT-3) in human retinal endothelial cells. Biochem J 1996; 318: 313-317.

162. Heilig CW, Concepcion LA, Riser BL, Freytag SO, Zhu M, Cortes $\mathrm{P}$. Overexpression of glucose transporters in rat mesangial cells cultured in a normal glucose milieu mimics the diabetic phenotype. J Clin Invest 1995; 96: 1802-1814.

163. Heilig CW, Liu Y, England RL, et al. D-glucose stimulates mesangial cell GLUT1 expression and basal and IGF-I-sensitive glucose uptake in rat mesangial cells: implications for diabetic nephropathy. Diabetes 1997; 46: 1030-1039. 